\title{
Qualidade da carne de cordeiros confinados recebendo diferentes relações de volumoso:concentrado na dieta
}

\author{
Quality of meat of confined lambs receiving \\ different concentrate:voluminous ratios in diet
}

\author{
Rafael Silvio Bonilha PINHEIRO ${ }^{1 *}$, André Mendes JORGE ${ }^{1}$, Raphael de Castro MOURÃO ${ }^{1}$, \\ Angelo POLIZEL NETO ${ }^{1}$, Ernani Nery de ANDRADE ${ }^{1}$, Helen Fernanda Barros GOMES ${ }^{1}$
}

\begin{abstract}
Resumo
Este estudo teve como objetivo avaliar a qualidade da carne de cordeiros terminados em regime de confinamento que receberam dietas com diferentes teores de concentrado. Foram utilizados 18 cordeiros $1 \frac{1}{2}$ Ile de France $1 / 2$ Santa Inês não castrados, com peso inicial de aproximadamente $15 \mathrm{~kg}$, distribuídos em dois lotes, representados pelo tratamento 1 (T1) animais que receberam na dieta relação volumoso:concentrado de 35:65 e (T2) cordeiros que receberam relação volumoso:concentrado de 65:35 até atingirem $32 \mathrm{~kg}$ de peso corporal em regime de confinamento, peso pré-determinado para o abate dos animais. Os cordeiros do tratamento 1 e 2 apresentaram valores similares de $\mathrm{pH}$, força de cisalhamento, perdas por cocção e capacidade de retenção de água da carne, com valores médios de 5,70,1,03 kgf/ $\mathrm{cm}^{2}, 35,20$ e 59,31\%, respectivamente. A relação volumoso:concentrado não influenciou na qualidade centesimal da carne dos cordeiros alimentados com dietas mais concentradas ou mais volumosas, para umidade, proteína, extrato etéreo e matéria mineral. Concluiu-se que os cordeiros terminados em confinamento recebendo diferentes teores de concentrado na dieta apresentaram qualidade da carne similar; portanto, a escolha da dieta vai depender do custo dos ingredientes no momento do confinamento.
\end{abstract}

Palavras-chave: alimentação; maciez da carne; ovinos; qualidade nutricional da carne.

\begin{abstract}
The objective of this study was to evaluate the meat quality of lambs terminated in confinement and fed diets with different concentrate contents. 18 non-castrated $1 / 2$ Ile de France $1 / 2$ Santa Inês lambs were used. Their initial weight was approximately $15 \mathrm{~kg}$ and they were divided into two separate groups represented by Treatment 1 (T1) - animals fed with diets containing the ratio voluminous:concentrate 35:65 - and Treatment 2 (T2) - lambs fed with diets containing the ratio voluminous:concentrate 65:35 until reaching $32 \mathrm{~kg}$ of body weight in confinement, which is the pre-established weight for slaughtering. T1 and T2 lambs presented similar values for $\mathrm{pH}$, shear force, losses due to cooking and water retention capacity; the average values found were $5.70,1.03 \mathrm{kgf} / \mathrm{cm}^{2}$, or 35.20 , and $59.31 \%$, respectively. The voluminous:concentrate ratio did not influence the centesimal quality of meat of lambs fed with more concentrated or more voluminous diets for humidity, protein, ethereal extract, and mineral matter. It can be concluded that lambs terminated in confinement fed with different concentrate contents diets presented similar meat quality; therefore, the diet choice depends on the cost of the ingredients at the time of the confinement.

Keywords: feeding; meat nutritional quality; meat softness; lambs.
\end{abstract}

\section{Introdução}

O aumento da oferta de carne ovina no Brasil está associado à melhoria dos sistemas de produção, visando atender à grande demanda do mercado consumidor. Principalmente nos grandes centros urbanos, muitas pessoas buscam adquirir produtos cárneos de maior qualidade provenientes principalmente de animais jovens terminados em confinamento. Porém, a ovinocultura de corte em sistemas intensivos de produção, encontra obstáculos em relação ao custo da dieta, um dos aspectos mais importantes na produção de carne (YAMAMOTO, 2006). De acordo com Hegarty, Meutze, Oddy (1999), pode-se obter cordeiros com boa qualidade da carne, e menores custos de produção; no entanto, é necessário um plano nutricional adequado, visando a utilização de dietas menos onerosas que atendam às exigências nutricionais dos animais.
Os alimentos que constituem a dieta dos ruminantes confinados são normalmente constituídos por concentrados e volumosos. Os concentrados, geralmente são os responsáveis pelo maior custo da alimentação dos ovinos mantidos neste sistema de produção. Os volumosos normalmente apresentam preços mais acessíveis que os concentrados e podem propiciar bom desempenho animal, desde que estes alimentos apresentem boa qualidade nutricional. Portanto, estudos que avaliem diferentes relações de volumoso:concentrado na dieta de cordeiros em regime de confinamento são válidos, no intuito de conhecer qual a melhor dieta a ser oferecida aos animais visando produção de carne de melhor qualidade. No entanto, tais estudos são praticamente inexistentes na literatura científica.

Recebido para publicação em 27/10/2007

Aceito para publicação em 3/1/2009 (002959)

${ }^{1}$ Departamento de Produção Animal, Faculdade de Medicina Veterinária e Zootecnia - UNESP, CP 560, CEP 18618-000, Campus de Botucatu, SP, Brasil,

E-mail: rafaelsbp@gmail.com

${ }^{*}$ A quem a correspondência deve ser enviada 
O nível nutricional, segundo Sainz (1996), está positivamente relacionado ao conteúdo de gordura na carcaça, sobretudo em animais alimentados com elevada quantidade de concentrado na dieta, podendo influenciar na qualidade da carne, como $\mathrm{pH}$, maciez, cor e perdas de peso ao cozimento, propriedades da carne que determinam atributos para a comercialização, como aparência e adaptabilidade aos processamentos industriais.

A terminação em confinamento com alimentação de elevado valor nutritivo constitui uma prioridade, quando o sistema de produção visa atingir elevado ganho de peso diário e a obtenção de carcaças e de carne de melhor qualidade (MADRUGA et al., 2005).

Pilar et al. (2003) descreveram que a heterose obtida pelo cruzamento entre raças ovinas pode propiciar maior velocidade de crescimento e melhor qualidade da carcaça e da carne destes animais. Portanto, a utilização de cruzamentos constitui uma forma de otimizar o crescimento e a qualidade do produto final e, consequentemente, favorece a cadeia produtiva, sendo válida sua utilização em sistemas intensivos de produção animal.

Considerando-se a importância da alimentação na qualidade da carne de cordeiros terminados em confinamento, justifica-se a necessidade de estudos com diferentes relações de volumoso:concentrado na dieta, visando identificar as possíveis diferenças na qualidade da carne de animais alimentados com maiores quantidades de concentrado na dieta.

Portanto, avaliou-se, neste trabalho, a influência da relação volumoso:concentrado na dieta de cordeiros não castrados $1 / 2$ Ile de France $1 / 2$ Santa Inês terminados em regime de confinamento quanto às qualidades física e centesimal da carne.

\section{Material e métodos}

\subsection{Animais experimentais}

Foram utilizados 18 cordeiros não castrados $1 / 2$ Ile de France $1 / 2$ Santa Inês, com peso inicial de $15 \mathrm{~kg}$ e com idade média de 50 dias de vida. Os animais foram distribuídos em dois grupos, recebendo dietas formuladas de acordo com as exigências preconizadas pelo NRC (1985). Os cordeiros foram terminados em regime de confinamento com alimentação ad libitum, sendo a dieta dos animais do tratamento 1 constituída por $35 \%$ de silagem de milho e $65 \%$ de concentrado, e a dieta dos ovinos do tratamento 2 constituída por $65 \%$ de silagem de milho e $35 \%$ de concentrado.

Amostras das dietas experimentais foram coletadas para determinação da composição bromatológica, conforme Silva e Queiroz (2002). A composição centesimal e bromatológica das dietas experimentais dos cordeiros que receberam diferentes relações de volumoso:concentrado na dieta encontram-se na Tabela 1.

Quando os cordeiros atingiram $32 \mathrm{~kg}$ de peso corporal, com aproximadamente 120 dias de idade, foram abatidos.

\subsection{Abate dos cordeiros e divisão dos cortes da carcaça}

Antes do abate os animais permaneceram em jejum de 16 horas de dieta sólida. O abate foi efetuado após insensibilização com eletronarcose, quando então foram seccionadas as veias jugulares e as artérias carótidas para sangria.

Após a retirada da pele, evisceração e retirada da cabeça e extremidades dos membros, as carcaças foram transferidas para câmara frigorífica a uma temperatura média de $4{ }^{\circ} \mathrm{C}$ por aproximadamente 24 horas. Ao final desse período, as carcaças foram divididas longitudinalmente em duas partes, e posteriormente seccionadas em cinco regiões anatômicas, conforme Garcia (1998): paleta, pescoço, costelas, lombo e perna (Figura 1).

As paletas das meias carcaças esquerda e direita de cada cordeiro foram identificadas, armazenadas em saco de polietileno, e congeladas por dois meses em freezer a $-18^{\circ} \mathrm{C}$, para determinações posteriores da qualidade da carne.

\subsection{Determinações da qualidade da carne}

As paletas foram descongeladas em geladeira a $10^{\circ} \mathrm{C}$, por 20 horas, dentro dos sacos plásticos. Após este período, com auxílio de bisturi e faca, foram desossadas as paletas da meia carcaça direita, para retirada de todos os músculos que compõem este corte. Após a retirada dos músculos, os mesmos, foram desprovidos de gordura subcutânea. Em seguida, foram identificados os conjuntos de todos os músculos de cada paleta e triturados em multiprocessador para homogeneização visando as análises de composição centesimal, que foram realizadas seguindo-se as recomendações da AOAC (1995). As paletas da meia carcaça esquerda também foram desossadas, porém, para retirada do músculo Triceps brachii, que também foi desprovido de gordura de cobertura. Neste músculo foi determinada a qualidade física da carne.

Tabela 1. Composição centesimal dos ingredientes e bromatológica das dietas experimentais.

\begin{tabular}{lcc}
\hline \multicolumn{1}{c}{ Ingrediente (\%) } & \multicolumn{2}{c}{$\begin{array}{c}\text { Relação volumoso: } \\
\text { concentrado }\end{array}$} \\
\hline & $35: 65$ & $65: 35$ \\
Silagem de milho & 35,00 & 65,00 \\
Grão de milho moído & 36,48 & 15,33 \\
Farelo de trigo & 16,10 & 5,30 \\
Farelo de soja & 10,00 & 11,20 \\
Sal comum & 0,50 & 0,50 \\
Fosfato bicálcico & 0,85 & 0,85 \\
Calcário calcítico & 0,42 & 0,42 \\
Suplemento mineral ${ }^{1}$ & 0,40 & 0,40 \\
Ureia $^{\quad \text { Composição bromatológica (\%) }}$ & 1,00 \\
& 0,25 & 49,36 \\
Matéria seca & 68,11 & 2,63 \\
Energia metabolizável (Kcal/kg de MS) & 2,57 & 15,97 \\
Proteína bruta & 15,99 & 41,21 \\
Fibra em detergente neutro & 36,08 & 16,93 \\
Fibra em detergente ácido & 12,97 & \\
\hline
\end{tabular}

${ }^{1}$ (nutrientes por quilograma do produto): fósforo $80 \mathrm{~g}$; cálcio $140 \mathrm{~g}$; magnésio $7 \mathrm{~g}$; enxofre 12g; sódio 133g; zinco $4.200 \mathrm{mg}$; cobre $300 \mathrm{mg}$; manganês $800 \mathrm{mg}$; ferro $1500 \mathrm{mg}$; cobalto $100 \mathrm{mg}$; iodo $150 \mathrm{mg}$; selênio $15 \mathrm{mg}$; flúor (máx) $800 \mathrm{mg}$; solubilidade do fósforo em ácido cítrico a $2 \%$ (mínimo) $95 \%$. 
A medida de $\mathrm{pH}$ foi determinada por meio de um peagômetro digital, introduzindo o eletrodo diretamente no músculo determinado (Triceps brachii). A capacidade de retenção de água foi calculada utilizando-se a metodologia descrita por Hamm, citada por Silva Sobrinho (1999).

Para determinar a cor da carne foi utilizado o colorímetro Minolta Chrome Meter CR-300, operando no sistema CIE ( $\mathrm{L}^{*}$ luminosidade, $\mathrm{a}^{*}$ intensidade de vermelho, $\mathrm{b}^{*}$ intensidade de amarelo), calibrado para um padrão branco em ladrilho.

Para a realização das perdas por cocção, foi utilizado um forno a gás pré-aquecido à temperatura de $170^{\circ} \mathrm{C}$. Amostras de carnes cruas foram pesadas e colocadas em bandejas com grelhas de ferro e novamente pesadas. Em seguida foram transferidas para o forno, onde permaneceram até a temperatura interna do centro da amostra atingir $75^{\circ} \mathrm{C}$. Após isto, as bandejas com as grelhas e amostras foram retiradas do forno e, quando esfriaram, pesadas novamente para o cálculo da percentagem de perda de água durante o cozimento.

Para a força de cisalhamento foram utilizadas as mesmas amostras da análise de perdas de água por cocção, as quais, após serem pesadas, foram cortadas em pedaços de aproximadamente $1,5 \times 1,5 \times 3,0 \mathrm{~cm}$ e submetidas ao corte no sentido transversal das fibras musculares, através da lâmina Warner-Bratzer acoplada ao aparelho Texture Analyser, sendo os valores expressos em $\mathrm{kgf} / \mathrm{cm}^{2}$.
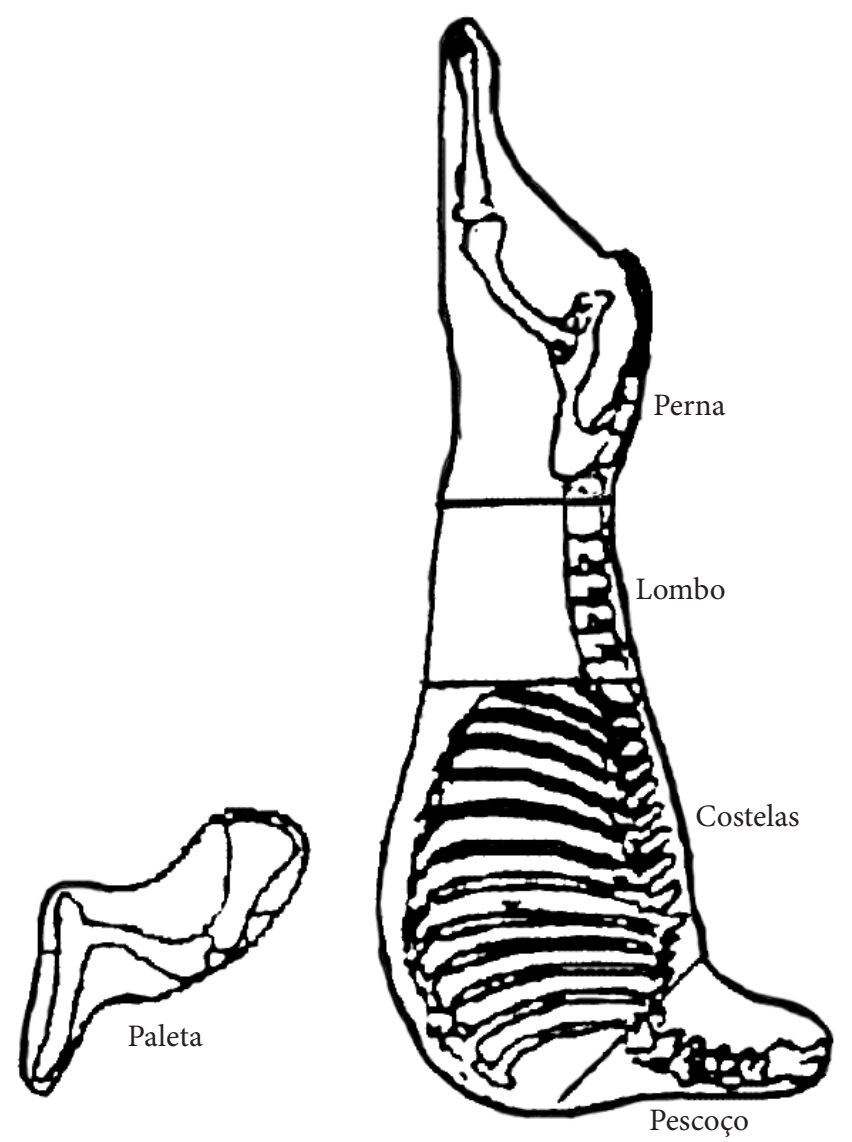

Figura 1. Cortes da meia carcaça esquerda dos animais experimentais.

\subsection{Delineamento experimental}

Foi utilizado o delineamento inteiramente casualizado, com dois tratamentos e nove repetições. A análise de variância foi conduzida segundo procedimentos do programa estatístico Statistical Analysis System (SAS, 1996), considerando-se o nível de significância de 5\%. O modelo estatístico utilizado foi:

$\mathrm{Yij}=\mu+\mathrm{Ti}+\mathrm{Eij}$

em que Yij = valor observado para a característica analisada; $\mu=$ é a média geral; $\mathrm{Ti}=$ representa o efeito do tratamento i; Eij = equivale ao erro experimental.

\section{Resultados e discussão}

A qualidade centesimal da carne de cordeiros não castrados $1 / 2$ Ile de France $1 / 2$ Santa Inês alimentados com diferentes teores de concentrado na dieta encontram-se na Tabela 2.

Os percentuais de umidade da carne dos cordeiros alimentados com diferentes relações de volumoso:concentrado foram próximos ( $\mathrm{p}>0,05$ ), com valor médio de 74,05\%. Resultados obtidos por Zeola et al. (2004) ao avaliarem cordeiros da raça Morada Nova terminados em confinamento recebendo diferentes teores de concentrado constataram que as dietas utilizadas não influenciaram os valores de umidade do músculo Semimembranosus, condizentes, portanto, com os resultados deste estudo (Tabela 2).

Perez et al. (2002), ao avaliarem o efeito do peso ao abate de cordeiros da raça Santa Inês quanto às propriedades químicas da carne, encontraram percentuais de umidade no músculo Longissimus dorsi de 73,90\% para cordeiros abatidos com $35 \mathrm{~kg}$ de peso corporal, semelhantes aos valores obtidos neste trabalho (Tabela 2) e também ao peso de abade dos animais.

O teor de extrato etéreo não diferiu $(p>0,05)$ entre a carne dos cordeiros do tratamento 1 e 2, com valor médio de 5,47\%. Ao avaliarem a qualidade da carne de cordeiros castrados e não castrados confinados sob dois fotoperíodos, Klein Júnior, Siqueira, Roça (2006) encontraram teores de extrato etéreo superiores ao deste estudo (Tabela 2) para os músculos do mesmo corte de carcaça utilizado neste trabalho. Souza et al. (2002) obtiveram valores de extrato etéreo para carne de cordeiros $1 / 2$ Ile de France $1 / 2$ Santa Inês de 2,54\% inferiores ao da carne dos cordeiros utilizados nesta pesquisa (Tabela 2). Apesar do mesmo cruzamento, sistema de terminação e peso de abate semelhantes,

Tabela 2. Médias e erros padrão da qualidade centesimal dos músculos do corte da paleta de cordeiros alimentados com diferentes teores de concentrado na dieta.

\begin{tabular}{lrrrr}
\hline \multicolumn{1}{c}{ Variável (\%) } & \multicolumn{1}{c}{ T1 } & T2 & Teste F & CV (\%) \\
\hline Umidade & $73,82 \pm 0,65$ & $74,28 \pm 0,42$ & $1,76^{\mathrm{NS}}$ & 1,49 \\
Extrato etéreo & $5,81 \pm 0,49$ & $5,13 \pm 0,48$ & $1,75^{\mathrm{NS}}$ & 14,16 \\
Matéria mineral & $1,16 \pm 0,04$ & $1,17 \pm 0,04$ & $2,04^{\mathrm{NS}}$ & 3,88 \\
Proteína & $19,21 \pm 0,59$ & $19,42 \pm 0,42$ & $1,29^{\mathrm{NS}}$ & 2,65 \\
\hline \multicolumn{4}{l}{ T1 = Cordeiros alimentados com dieta contendo relação volumoso:concentrado de 35:65. } \\
T2 = Cordeiros alimentados com dieta contendo relação volumoso:concentrado de 65:35. \\
CV = Coeficiente de variação. NS = Não significativo (p > 0,05).
\end{tabular}


entre este estudo e o de Souza et al. (2002), o teor de extrato etéreo obtido foi diferente em ambos, sendo importante avaliar outras questões, como a nutrição e a localização do músculo estudado, pois podem propiciar diferenças na composição da carne.

Cordeiros alimentados com maior quantidade de concentrado na dieta obtiveram valores de matéria mineral e de proteína nos músculos do corte da paleta próximos $(\mathrm{p}>0,05)$ ao da carne dos animais que tiveram acesso a alimentação com maior quantidade de volumoso (Tabela 2). Resultados semelhantes ao deste estudo para o percentual de proteína na carne de cordeiros terminados em confinamento foram encontrados por Zeola et al. (2004). Os valores de matéria mineral da carne deste trabalho (Tabela 2) estão de acordo com as informações da literatura (SOLOMON, LINCH, LOUGH, 1992; SOUZA et al., 2001; SOUZA et al., 2002; MADRUGA et al., 2006).

A composição centesimal dos músculos do corte da paleta de cordeiros terminados em confinamento foi próxima $(p>0,05)$ entre os tratamentos estudados (Tabela 2). Isso pode ter ocorrido pelo fato das dietas utilizadas neste experimento apresentarem proporções semelhantes de proteína e de energia, conforme descrito na Tabela 1.

As médias da qualidade física do músculo Triceps brachii de cordeiros não castrados $1 / 2$ Ile de France $1 / 2$ Santa Inês alimentados com diferentes teores de concentrado na dieta encontram-se na Tabela 3.

Os cordeiros alimentados com relação volumoso:concentrado de 35:65 apresentaram valor de $\mathrm{pH}$ da carne próximo $(\mathrm{p}>0,05)$ ao da carne dos animais que receberam dieta mais volumosa, com valor médio de pH de 5,69. De acordo com Zeola et al. (2002), diferentes níveis de concentrado na dieta de cordeiros terminados em confinamento não influenciaram o valor do $\mathrm{pH}$ da carne, que estão de acordo com os resultados obtidos neste estudo (Tabela 3).

Os valores de $\mathrm{pH}$ da carne dos cordeiros deste trabalho estão em conformidade com os valores normais da carne ovina de acordo com informações da literatura científica (APPLE et al., 1995; ROTA et al., 2004; ALMEIDA et al., 2004; PINHEIRO, 2006). Segundo Bonagurio et al. (2003), o pH da carne modifica suas características de qualidade (cor, capacidade de retenção de água

Tabela 3. Médias e erros padrão da qualidade física do músculo Triceps brachii de cordeiros alimentados com diferentes teores de concentrado na dieta.

\begin{tabular}{lrrrc}
\hline \multicolumn{1}{c}{ Variável } & \multicolumn{1}{c}{ T1 } & \multicolumn{1}{c}{ T2 } & Teste F & CV (\%) \\
\hline $\mathrm{pH}$ & $5,68 \pm 0,03$ & $5,71 \pm 0,04$ & $0,29^{\mathrm{NS}}$ & 1,38 \\
$\mathrm{~L}^{*}$ & $40,57 \pm 0,73$ & $41,61 \pm 0,97$ & $0,67^{\mathrm{NS}}$ & 4,40 \\
$\mathrm{a}^{*}$ & $14,37 \pm 0,29$ & $14,43 \pm 0,56$ & $0,01^{\mathrm{NS}}$ & 6,23 \\
$\mathrm{~b}^{*}$ & $2,80 \pm 020$ & $2,74 \pm 0,39$ & $0,02^{\mathrm{NS}}$ & 22,74 \\
Maciez $\left(\mathrm{kgf} / \mathrm{cm}^{2}\right)$ & $1,03 \pm 0,12$ & $1,02 \pm 0,05$ & $0,02^{\mathrm{NS}}$ & 14,55 \\
CRA (\%) & $60,20 \pm 0,58$ & $58,42 \pm 1,56$ & $1,14^{\mathrm{NS}}$ & 3,98 \\
Perdas por cocção (\%) & $35,00 \pm 0,52$ & $35,39 \pm 0,25$ & $0,45^{\mathrm{NS}}$ & 2,34 \\
\hline
\end{tabular}

$\mathrm{T} 1$ = Cordeiros alimentados com dieta contendo relação volumoso:concentrado de 35:65. T2 = Cordeiros alimentados com dieta contendo relação volumoso:concentrado de 65:35. CV = coeficiente de variação. $C R A=$ capacidade de retenção de água. NS = Não significativo $(\mathrm{p}>0,05)$. e maciez), além de alterar as características organolépticas da carne. Portanto, o pH da carne é um dos parâmetros de qualidade mais importantes, pois interfere nos demais atributos.

A cor da carne dos cordeiros terminados em confinamento que receberam maior quantidade de concentrado na dieta apresentou valores similares $(\mathrm{p}>0,05)$ aos da carne dos ovinos que receberam maior quantidade de volumoso na dieta, com valores médios de $\mathrm{L}^{*}, \mathrm{a}^{\star}$ e b* de 41,09, 14,40 e 2,77, respectivamente. Russo et al. (1999) ao avaliarem diferentes fontes de energia na alimentação de cordeiros não constataram efeito da dieta na cor do músculo Longissimus lumborum e apresentaram valores semelhantes aos deste estudo (Tabela 3) para os teores de vermelho, amarelo e também para a luminosidade da carne.

Zeola et al. (2002) ao utilizarem níveis crescentes de concentrado na dieta $(30,45$ e $60 \%)$ de cordeiros em confinamento, constataram que não houve influência para os valores de cor da carne, estando de acordo com os resultados deste trabalho (Tabela 3).

A maciez foi semelhante $(\mathrm{p}>0,05)$ entre a carne dos cordeiros dos tratamentos 1 e 2 , com valor médio de $1,02 \mathrm{kgf} / \mathrm{cm}^{2}$, sendo os valores da força de cisalhamento inferiores aos encontrados por Villas Bôas et al. (2003) ao trabalharem com cordeiros superprecoces da raça Hampshire Down, abatidos com peso corporal de aproximadamente $28 \mathrm{~kg}$. Pinheiro (2006) obteve valores de força de cisalhamento superiores ao deste trabalho (Tabela 3), ao avaliar o músculo Tríceps brachii $\left(2 \mathrm{kgf} / \mathrm{cm}^{2}\right) \mathrm{e}$ também o músculo Longissimus lumborum $\left(1,79 \mathrm{kgf} / \mathrm{cm}^{2}\right)$ de cordeiros abatidos com peso de $32 \mathrm{~kg}$. Podendo-se afirmar, diante destes resultados, que a maciez da carne dos cordeiros deste estudo foram superiores aos dos trabalhos citados anteriormente.

A maciez da carne é um importante parâmetro de qualidade, portanto, carnes mais macias apresentam um maior valor comercial, sendo uma característica importante em sistemas de terminação de cordeiros e que foi obtida na carne dos animais deste estudo (Tabela 3) em ambos os tratamentos experimentais.

No presente trabalho, a capacidade de retenção de água e as perdas por cocção da carne não diferiram $(\mathrm{p}>0,05)$ entre o músculo Triceps brachii de cordeiros alimentados com diferentes teores de concentrado na dieta, com valores médios de 59,31 e $35,19 \%$, respectivamente. Klein Júnior, Siqueira, Roça (2006), ao avaliar a qualidade da carne de cordeiros não castrados e castrados terminados em confinamento, constataram percentuais de capacidade de retenção de água no músculo Longissimus lumborum inferiores aos resultados desta pesquisa, provavelmente pela diferente metodologia adotada para tal análise. Valores semelhantes aos apresentados neste trabalho para perdas por cocção da carne ovina foram encontrados por Ockerman et al. (1982), Kadim et al. (1993), Babiker, El Khider, Shafie (1990).

\section{Conclusões}

Cordeiros não castrados terminados em regime de confinamento recebendo diferentes teores de concentrado na dieta apresentaram composição centesimal semelhante nos músculos do corte da paleta. 
O músculo Triceps brachii dos cordeiros alimentados com dieta mais concentrada apresentou valores de $\mathrm{pH}$, maciez, perdas por cocção e capacidade de retenção de água similares aos do músculo dos cordeiros alimentados com dieta mais volumosa. Diante destes resultados, a melhor escolha da dieta dos cordeiros vai depender do custo dos ingredientes no momento do confinamento.

\section{Referências bibliográficas}

ALMEIDA JÚNIOR, G. A. et al. Qualidade da carne de cordeiros criados em creep feeding com silagem de grãos úmidos de milho. Revista Brasileira de Zootecnia, v. 33, n. 4, p. 1039-1047, 2004.

APPLE, J. K. et al. Effects of restraint and isolation stress and epidural blockade on endocrine and blood metabolite status, muscle glycogen metabolism, and incidence of dark-cutting Longissimus muscle of sheep. Journal of Animal Science, v. 73, n. 8, p. 2295-2307, 1995.

ASSOCIATION OF OFFCIAL ANALYTICAL CHEMISTS - AOAC. Official methods of analyses chemists. 16 ed. Arlington, 1995.

BABIKER, S. A.; EL KHIDER, I. A.; SHAFIE, S. A. Chemical composition and quality attributes of goat meat and lamb. Meat Science, v. 28, n. 4, p. 273-277, 1990.

BONAGURIO, S. et al. Qualidade da carne de cordeiros Santa Inês puros e mestiços com Texel abatidos com diferentes pesos. Revista Brasileira de Zootecnia, v. 32, n. 6, p. 1981-1991, 2003.

GARCIA, C. A. Avaliação do resíduo de panificação "biscoito" na alimentação de ovinos e nas características quantitativas e qualitativas da carcaça. 1998. 79 f. Dissertação (Mestrado em Zootecnia) - Faculdade de Ciências Agrárias e Veterinárias, Universidade Estadual Paulista.

HEGARTY, R. S.; MEUTZE, S. A.; ODDY, V. H. Effects of protein and energy supply on the growth and carcass composition of lambs from differing nutritional histories. Journal of Agricultural Science, v. 132, n. 3, p. 361-375, 1999.

KADIM, I. T. et al. Meat quality and muscle fibre type characteristics of Southdown rams from high and low backfat selection lines. Meat Science, v. 33, n. 1, p. 97-109, 1993.

KLEIN JÚNIOR, M. H.; SIQUEIRA, E. R. S.; ROÇA, R. O. Qualidade da carne de cordeiros castrados e não-castrados confinados sob dois fotoperíodos. Revista Brasileira de Zootecnia, v. 35, n. 4, p. 1872-1879, 2006.

MADRUGA, M. S. et al. Qualidade da carne de cordeiros Santa Inês terminados com diferentes dietas. Revista Brasileira de Zootecnia, v. 34, n. 1, p. 309-315, 2005.

MADRUGA, M. S. et al. Efeito do genótipo e do sexo sobre a composição química e o perfil de ácidos graxos da carne de cordeiros. Revista Brasileira de Zootecnia, v. 35, n. 4, p. 1838-1844, 2006.

NATIONAL RESEARCH COUNCIL - NRC. Nutrient requeriments of sheep. New York: National Academy Press, 1985. 99 p.

OCKERMAN, H. W. et al. Influence of type (wooled or hair) and breed on growth and carcass characteristics and sensory properties of lamb. Journal of Food Science, v. 47, n. 4, p. 1365-1368, 1982.

PEREZ, J. R. O. et al. Efeito do peso ao abate de cordeiros Santa Inês e Bergamácia sobre o perfil de ácidos graxos, colesterol e propriedades químicas. Revista Ciência e Tecnologia de Alimentos, v. 22, n. 1, p. 11-18, 2002.
PILAR, R. C. et al. Desempenho de cordeiros Merino Australiano e cruza Ile de France $\times$ Merino Australiano. Ciência e Agrotecnologia, Edição Especial, p. 1652-1661, 2003.

PINHEIRO, R. S. B. Aspectos quantitativos da carcaça e qualitativos da carne de ovinos de diferentes categorias. Jaboticabal, 2006. 105p. Dissertação (Mestrado em Zootecnia) - Faculdade de Ciências Agrárias e Veterinárias, Universidade Estadual Paulista.

ROTA, E. L. et al. Efeitos do cruzamento de carneiros da raça Texel com ovelhas Corriedale e Ideal sobre a qualidade da carne. Revista Brasileira Agrociência, v. 10, n. 4, p. 487-491, 2004.

RUSSO, C. et al. Effect of diet energy source on the chemical-physical characteristics of meat and depot fat of lambs carcasses. Small Ruminant Research, v. 33, n. 1, p. 77-85, 1999.

SAINZ, R. D. Qualidade das carcaças e da carne ovina e caprina. In: REUNIÃO ANUAL DA SOCIEDADE BRASILEIRA DE ZOOTECNIA, 33, 1996, Fortaleza. Anais... Fortaleza: Sociedade Brasileira de Zootecnia, 1996. p. 3-14.

SAS INSTITUTE. User's Guide to Statistics. Version 6.12. Cary, USA: North Caroline State University, 1996.

SILVA SOBRINHO, A. G. Body composition and characteristics of carcass from lambs of different genotypes and ages at slaughter. Palmerston North, 1999. $54 \mathrm{f}$. Dissertation (PostDoctorate in Sheep Meat Production) - Massey University.

SILVA, D. J.; QUEIROZ, A. C. Análise de Alimentos: métodos químicos e biológicos. 5 ed. Viçosa: Imprensa Universitária, 2002. 235 p.

SOLOMON, M. B.; LYNCH, G. P. LOUGH, D. S. Influence of dietary palm oil supplementation on serum lipid metabolites, carcass characteristics and lipid composition of carcass tissues of growing ram and ewe lambs. Journal of Animal Science, v. 70, n. 9, p. 2746-2751, 1992.

SOUZA, X. R. et al. Composição de carnes de cordeiros machos e fêmeas de dois grupos genéticos abatidos em diferentes pesos. In: CONGRESSO BRASILEIRO DE CIÊNCIA E TECNOLOGIA DE CARNES: Carne: Qualidade e Segurança para os consumidores do novo milênio, 1, 2001, São Pedro. Anais...

SOUZA, X. R. et al. Composição centesimal do músculo Biceps femoris de cordeiros em crescimento. Ciência e Agrotecnologia, Edição Especial, p. 1507-1513, 2002.

VILLAS BÔAS, A. S. et al. Idade a desmama e manejo alimentar na produção de cordeiros superprecoces. Revista Brasileira de Zootecnia, v. 32, n. 6, p. 1969-1980, 2003.

YAMAMOTO, S. M. Desempenho e características de carcaça de cordeiros terminados em confinamento com dietas contendo silagem de peixe. 2006. 95p. Tese (Doutorado em Zootecnia) Faculdade de Ciências Agrárias e Veterinárias, Universidade Estadual Paulista - Unesp.

ZEOLA, N. M. B. L. et al. Influência de diferentes níveis de concentrado sobre a qualidade da carne de cordeiros Morada Nova. Revista Portuguesa de Ciências Veterinárias, v. 97, n. 544, p. 175-180, 2002.

ZEOLA, N. M. B. L. et al. Composição centesimal da carne de cordeiros submetidos a dietas com diferentes teores de concentrado. Ciência Rural, v. 34, n. 1, p. 253-257, 2004. 